\title{
BRITS-A HOLISTIC FRAMEWORK FOR HEDGING SHAREHOLDER VALUE IN IT DEPENDENT BUSINESS
}

Christer Magnusson, and Louise Yngström

Department of Computer and Systems Sciences,

\begin{abstract}
This paper explains and reports on a risk management framework and discusses the experiences of the application of the framework in trade and industry. The framework encompasses a risk analysis method to financially measure loss exposures due to IT perils, a tool to estimate security awareness, and a vehicle to financial hedging of IT risks.
\end{abstract}

Key words: risk analysis, financial risk, IT risk, hedging

\section{INTRODUCTION}

A change during the last few years is the shift in technology; mainframe computer systems that were previously homogenous units with proprietary communications protocols (such as SNA/SNI and DECnet) are now integrated with or replaced by UNIX- and Windows-based systems at offices, customers, suppliers, homes and vehicles, connected through the open, interoperable protocol suite TCP/IP.

The migration from proprietary systems to the interoperable Internet platform has had at least one drawback - security (see figure 1). 


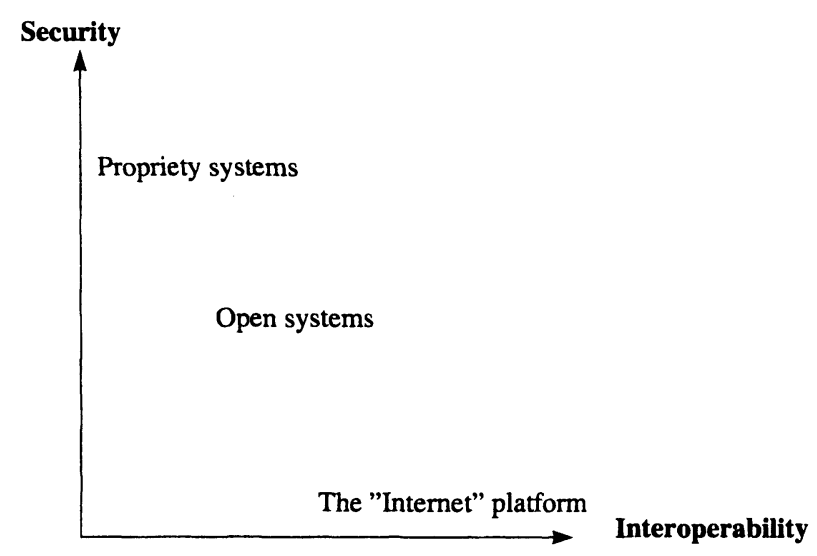

Figure 1. A non-secure Migration

Dividend and price rise of companies' shares are the primary interests of the shareholders, and a precondition for delivering shareholder value for most businesses today is interoperable Internet platform. Accordingly, malfunctions of companies' IT-operations can directly spoil otherwise prosperous companies' cash flow statements and balance sheets, and, thus, reduce their shareholders' capital substantially.

For example, business interruptions due to IT perils could reduce the income stream and cause extra expenses, which will decrease the operating profit and the cash flow. Moreover, liability claims and/or loss of property could reduce the capital in the balance sheet. These IT related loss exposures may also increase the weighted average capital cost.

Besides paying attention to the performance of a company, it should therefore also be vital for shareholders and equity fund managers to be aware of a company's financial exposures due to IT perils and the management of these.

\section{THE OBJECTIVE}

This paper attempts to briefly explain a risk management framework and discuss the experiences of the application of the framework in trade and industry. The framework encompasses a risk analysis method to financially measure loss exposures due to IT perils, a tool to estimate security awareness, and a vehicle to financial hedging of IT risks; together making up a methodology for hedging shareholder value.

Methods to value financial performance of companies, IT, security and financial tools for hedging losses, all of these entities have to be considered 
to secure shareholders' investments. That is why the entities need to be studied in a context - as a system - and not separately.

The approach chosen in the research for studying the entities as a system was the System-Holistic Approach, developed by Louise Yngström [Yngström 1996]. She defines her approach as:

"The approach is very simple: it starts with something known to exist in reality to the investigator. Upon this is suggested, tried and built external objective knowledge from elsewhere. Through these mental processes internal subjective new knowledge is formed. Thus a subjective epistemological framework is formed out of the objective knowledge."

The arguments for choosing the System-Holistic Approach as research approach were:

- The approach to build on an, for the investigator known, existing entity with other objective known entities, and from this combination construct new, subjective knowledge, gave me the methodology to create BRITS; I started with IT and security, added formulas for the valuation of companies and financial risk transfer tools, and from these objective entities, constructed the framework BRITS.

- It is an action-oriented and explorative research methodology, suitable for empirical frameworks.

- The System-Holistic Approach is in turn based on General Systems Theories, Cybernetics, Soft System Methodology and General Living Systems.

- The approach regards IT-security as a part of something larger, a system, and thus not just considering security as a technical, isolated part of a software or hardware. Furthermore, it stresses holistics. Accordingly, by using this approach, the risk to see IT-security as a merely technical issue is reduced.

The systemic, trans-disciplinary approach made it possible to unify and integrate valuation of companies, IT, security, finance and financial risk transfer into a system, BRITS. In addition, the Systemic-Holistic research approach, to build on to the researcher known entities (IT and security) with other objective known entities (finance and financial risk transfer), offered the methodology to create new, subjective knowledge: the framework BRITS (see figure 2). 


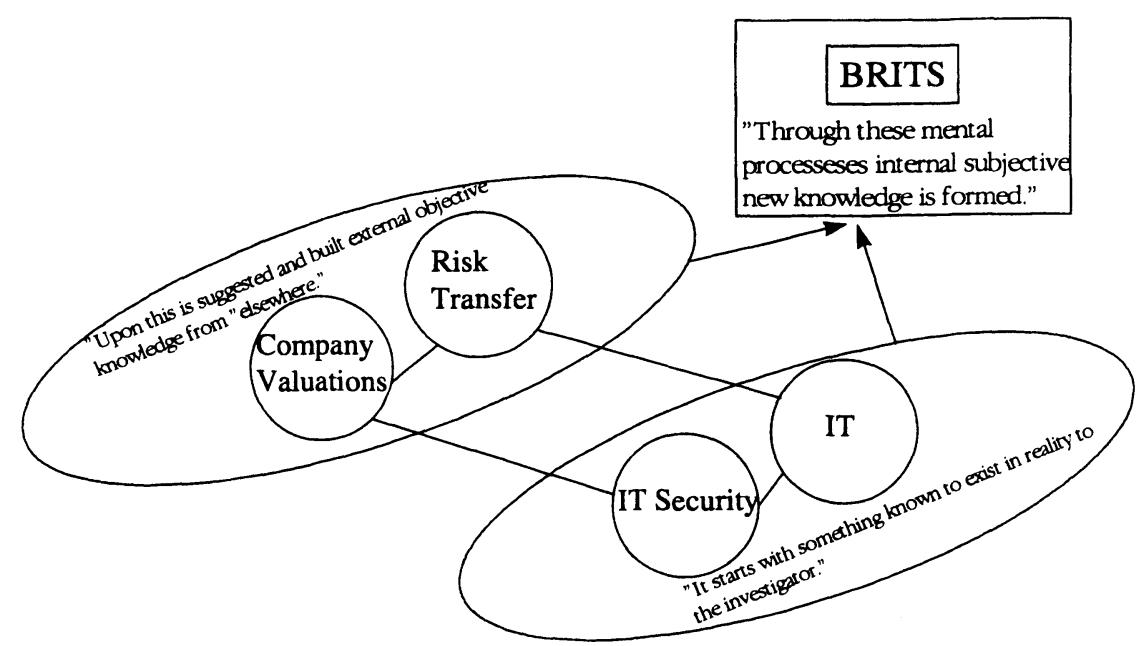

Figure 2. The Systemic-Holistic Research Approach

The work included the design of BRITS, and the implementation of the framework in trade and industry.

At the time of the realization of the survey of related risk and security analyses, no models, methodologies and approaches for risk and security analyses existed that used financial hedging against IT risks as the primary measure to secure shareholder value. Nevertheless, there are structures in the methods studied that have been utilized and developed in the framework [Clark, et. al., 1988], [ITSEC, 1990], [ESPD, 1992], [BSI, 1993, 1995, 1998], [TCSEC, 1983; 1985], [ITSEC, 1990].

\section{THE FRAMEWORK BRITS}

The framework "Business Requirements on IT-Security" (BRITS) focuses on:

- the company's profit and loss account, balance sheet and cash flow statement,

- financial consequences of IT perils,

- financial hedging of IT risks, and

- estimations of security awareness.

The need for financial hedges and technical countermeasures against IT perils depends solely on the estimated effect IT perils may have on the 
market value of the company; there are no other reasons for a commercial company to spend any of its resources on financial protection and IT security measures.

\subsection{The BRITS Value Formula}

The Discounted Cash Flow (DCF) [Copeland et al., 1995] formula was extended to encompass the financial exposures of IT perils. In this new form the formul was named the Business Requirements on IT Security (BRITS) Value Formula.

According to the DCF theory, the present value of any asset is the future cash flow that it is expected to generate, discounted at an appropriate rate of return. Anything that could threaten the future cash flow generation threatens also the values of companies. Therefore, companies must have prepared financial arrangements to hedge against consequences of loss exposures, if their cash flows are threatened due to these operative exposures.

According to the DCF theory, the present value of any asset is the future cash flow that it is expected to generate, discounted at an appropriate rate of return. Anything that could threaten the future cash flow generation threatens also the values of companies.

There are some fundamental key figures in a DCF valuation that determine the value of a company. These are:

- the progress of the Free Cash Flow ( especially, the Net Operating

Profit Less Adjusted Taxes),

- the return on invested capital relatively the cost of capital (the

Weighted Average Capital Cost), and

- the estimation of the perpetual growth of the NOPLAT.

Today, in most companies, IT is a prerequisite to operate the business. Consequently, IT incidents will (almost) undoubtedly reflect the FCF and the return on capital. Moreover, the perpetual growth of a company may be downward adjusted. As a result, the total value of a company will be reduced.

If it is generally possible to capture the "IT risk" on the stock markets in something equivalent to the beta ${ }^{1}$, is difficult to predict. However, how exposed companies are to IT perils and how these companies manage and financially hedge IT risks is a crucial issue for shareholders and should be incorporated in the valuation of companies.

${ }^{1}$ Publicly traded companies' level of risk are statistically measured by the stock exchanges against the market's general fluctuations over time in an index called beta. As an example: a stock with the beta 0,75 has less systematic risk than the average stock with 1,0 in beta. 
In the BRITS value formula (see figure 3), the Free Cash Flow is reduced with the calculated amount for the estimated damage exposures (de). The Weighted Average Capital Cost reflects the company's risk of losses due to IT perils. This means that the risk premium (the "Beta") increases with the proportion of the company's financial consequences due to IT perils. Moreover, the perpetuity growth rate $(\mathrm{g})$ in the Net Operating Profit Less Adjusted Taxes is reduced with the company's estimated damage exposures (de). The result of the calculation is a discounted value of a company, which reflects its inherent risks for losses due to IT perils.

\begin{tabular}{|c|c|c|}
\hline 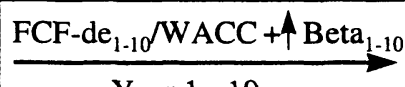 & $\stackrel{\text { FCF-de }}{\stackrel{11}{ } / \text { WACC }+\uparrow \text { Beta }-(\mathrm{g}-\mathrm{de})} \longrightarrow$ & $\begin{array}{l}\text { The company's } \\
\text { value (discounted }\end{array}$ \\
\hline Year $1-10$ & Year 11 & to present value) \\
\hline
\end{tabular}

Figure 3. The BRITS Value Formula

The difference between the original DCF value and the BRITS value (incorporating the damage exposures) is the amount that needs to be financially hedged in order to secure shareholders' investments. Further, measures to hedge IT security exposures need to be structured in a Value Based Security Management (VBSM) context; there are no other reasons for spending resources on financial and technical measures than a clear link to secure shareholder value.

\subsection{The Financial Hedge - the Captive}

The traditional, commercial insurance market's conservative approach to new types of risks, its volatility and business model, may at least on the short term be an obstacle for providing capacity for IT perils. However, there are financial instruments that could be used to hedge against IT perils.

A captive concept (see figure 4) was used. The reason is that captives seem to be the most effective avenues to choose for hedging against IT dependent risks. Finite insurance could be used as a reinsurance arrangement for the captive. Moreover, contingent surplus notes, liability backed securities, and catastrophe bonds could be used as the second layer of retrocession cover [Magnusson 1999]. 


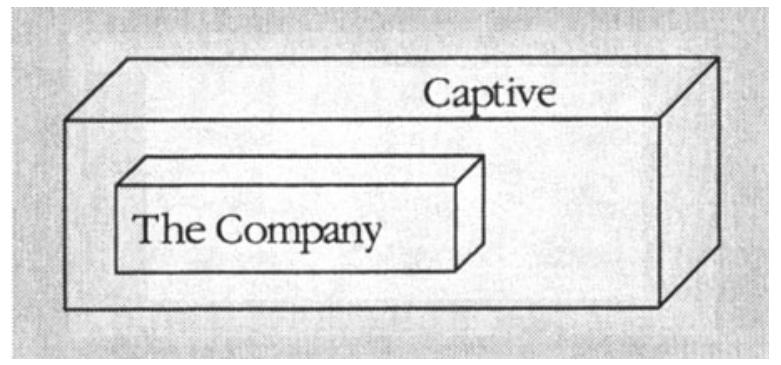

Figure 4. Hedging the Company

Primarily a captive insurance company is set up by its mother company to insure the corporation's own, internal risks. There are several reasons for a company to form a captive:

- obtaining cover for uninsurable risks or areas with restricted capacity,

- controlling the risk management program,

- reducing primary insurance costs,

- increasing limits on existing policies,

- taking larger group retention,

- broadening the scope and type of cover offered,

- providing access to reinsurance markets and - ultimately -

- writing third party underwriting.

A captive helps its owner(s) to increase deductibles, and thereby saves premiums for the owner(s). Business units (or cell owners) within a corporation (or a captive group) can keep smaller deductibles and insure themselves in the captive. These risks will be kept in the captive without any reinsurance, and the captive will only reinsure itself for catastrophe losses.

A captive contributes to increase its owners' positive cash flow; instead of paying the premium to direct insurers in the beginning of a year, the practice in the reinsurers' industry is to pay the premium after the insurance year. This means that the premiums are kept within the corporation more than 12 month longer than what had been the case without a captive. Besides improving the corporation's cash flow, the premiums can also be invested. The investment income stays within the captive, instead of belonging to the direct insurer.

\subsection{The database EmitL}

In the framework BRITS, existing financial hedge instruments were utilized and developed to provide cover against financial consequences of IT perils (see section 4.2). However, before these instruments can be used they 
require information about the financial risk to cover and the security awareness in the policy holders' IT operations. This requirement was met by developing the database Estimated Maximum information technology Loss (EMitL). In short EMitL operates as follows.

Based on companies' exposures for IT perils, the security in companies' computer systems is estimated by applying to the systems the approximately 1000 logic, administrative and physical security requirements in the database EMitL. The database bridges the lack of a common terminology between the company management and the world of finance and risk transfer on the one side and the technicians and security experts on the other side; the database simply "converts" financial terminology to IT security terminology, and vice versa. In this way, the vulnerabilities in IT can be explained in financial terms, and vice versa.

EMitL is based on the practical difficulties to fulfill the Law of Requisite Variety [Schoderbek et. al., 1985]. Instead the approach to view the IT systems as black boxes [Schoderbek et. al., 1985] was chosen. Based on this fundamental assumption, The following and more detailed directives were followed for the development of EMitL:

- It should be based on the following classification of IT security properties: Integrity, Availability, and Confidentiality.

- It should have a modular structure, based on well-defined IT-areas.

- Threats, weaknesses and vulnerabilities should be estimated in the different IT-areas in a structured way, however by no means complete.

- The security measures should thereafter be grouped into four security levels; there should be less measures - and thereby less security - at security level 1 than at the highest level, security level 4 .

- Each security level should consist of a set of "peer-of-securitymeasures", i.e. the measures for each level should be consistent as far as possible.

- The measures should be functional and not specify security products.

- The IT should be viewed purely as production resources, and their use for business services (products) should not be considered within the scope of this particular project.

\section{CONCLUSIONS AND DISCUSSION}

The framework has been used in several corporations; one of them is world leader in its business segment. The framework has been applied on different business segment, ranging from banking to logistics. The framework places financial and technical security measures in the company's heart: its market value. 
The BRITS framework contributes with the following:

- provides a formula to estimate the financial consequences of loss exposures due to IT perils;

- decreases the risk that companies are unaware of deficiencies in their financial cover or, if the worst comes to the worst, do not have any financial cover at all against IT perils;

- makes it possible to utilize existing financial hedge instruments to provide cover against financial consequences of IT perils;

- makes it possible to estimate the security awareness in existing ITplatforms;

- based on that information, existing security measures can be "priced" as they may reduce the estimated maximum loss figures - and thereby the costs for the financial hedges;

- reduces the risk for expensive sub-optimizations in IT security, since technicians can get a better understanding of which systems that are critical for the companies' financial results. This knowledge will enable them to better direct security measures;

- the costs for the loss exposure inherent in companies' business services or products can be estimated in a better way, and thereby be incorporated in the products' price;

- may help to develop the traditional risk transfer markets' possibilities to estimate IT risks, which may facilitate risk transfer to their customers; and

- may be used by venture capitalists in Initial Public Offerings (IPO), especially when introducing true Internet companies. BRITS may give prospective shareholders a better understanding of the risk for loss exposures in IPOs.

To reach the objectives with BRITS, it is vital that the executive management, and not the security director, risk manager or middle management in general, estimate the financial damage exposures that ensue from the company's dependency on IT. This does not imply however that they should be experts in either IT or IT security. Instead they should use their expert knowledge: the competence of the business process of the company; the in-depth knowledge of the income streams and operating and capital costs for their products; the company's liabilities to their customers; its suppliers' liabilities to the company; and their products' financial exposures to loss of property.

Even though the Systemic-Holistic Approach is BRITS' major strength, this approach includes at least one complication: it requires multidisciplinary competence. To be able to operate BRITS, at least the BRITS 
coordinator must have competence in all of the areas: IT, security, risk transfer and finance. The in-depth knowledge in these areas can vary, but the coordinator must be able to understand the connections and interfaces between the areas. People with such a background may be difficult to find.

BRITS is based on the fact that no security policies whatsoever will provide a 100 per cent security. Nevertheless, the security polices provided by the database EMitL must be up to date in accordance with the technology developments. If they do not comprise the latest technologies and at least some of their weaknesses, the IT staff will loose confidence in the policies. This is very difficult and also quite costly to achieve, and there are no signs that technology development will decrease in the future. Moreover, technology will become increasingly complex and even more difficult to survey.

The virtualization of the work process is another area of concern; it gets difficult when customers and/or joint venture partners, who need to be integrated in your Extranet, are your competitors, too. There are no preventive, technological solutions to this challenge in BRITS. Instead, this issue is handled by a more symbolic requirement on legally binding liability contracts with the partner/competitor.

Out-sourcing and temporary in-sourcing is another popular phenomena in today's business society, but this may also result in loyalty being outsourced and potential competitors or criminals being in-sourced. As in the previous challenge, prevention is limited to legal requirements.

There are some suggestions for further research within this area, which are specially interesting:

1. One is investigating the possibilities to develop a beta, which easily can be used to compare companies' dependencies on IT and loss exposures due to IT perils and that can be used generally at the stock markets.

2. In the framework BRITS contingent surplus notes, liability backed securities, and catastrophe bonds were used as the second layer of retrocession cover. The researcher had no practical previous knowledge from these tools himself. The reason is that the retrocession cover required was too small to make these tools cost-effective. Nevertheless, these instruments worked well for comprising IT risks, but it would be interesting to look more into this area.

3. Even though BRITS has been applied on a large company in this thesis, it is a scaleable framework, which also can be utilized for small companies (perhaps working in a flexible, virtual network consistent of highly specialized and innovative small companies). The solution for small companies is a cell captive, owned by several companies. Each company is responsible for their own risks (i.e. their cells) in the captive, but catastrophe cover is bought jointly. It would be interesting 
to see a case study especially on companies in the virtual and digital economy.

4. Venture capitalists may utilize BRITS in the processes of Initial Public Offerings (IPO); it may help prospective shareholders to better estimate and decide on their risk willingness. Especially venture capitalists launching true Internet companies should account for these companies' loss exposures due to IT perils and the companies' financial hedges of these exposures. Therefore, a research project investigating how loss exposures are handled in today's IPOs would be most welcome. My hypothesis is that the issue has not been addressed. If my hypothesis is correct, it would be interesting to see how the IPOs would have been adjusted, if the loss exposures had been taken into account in the first place.

5. Since BRITS is based on shareholder value, it is not applicable to noncommercial organizations. These organizations have other than financial goals to reach. It would be interesting to see an approach similar to BRITS applied in such a context, since modules EmitL, BRITS Value formula, and Hedge Captive may be exchanged and still use the BRITS framework.

6. Another area that requires further development is procedures for development, installation, configuration and operation of security applications. Today, there is a gap between the traditional security policies' more abstract descriptions of security requirements and the technical specifications and manuals. Clearly, there is a need for synchronization.

Independently of future research in this area, we are convinced that what is required is more of inter-disciplinary research. The reason is that the complexity of the virtual, networked and digitized economy demands such solutions and not only just another encryption algorithm or key exchange scheme. 


\section{REFERENCES}

[BSI, 1993], British Standards Institution, A Code of Practice for Information Security Management, ISBN 05802536 4, 1993.

[BSI, 1995], British Standards Institution, Information security management, Part 1. Code of practice for information security management systems, BS 7799, 1995.

[BSI, 1998], British Standards Institution, Information security management, Part 2. Specification for information security management systems, BS 7799, 1998.

[Clark. et. al., 1988], Clark, David D. And Wilson, David R., Evolution of a Model for Computer Integrity. 11:th National Computer Security Conference, 1988, USA.

[Copeland et al. 1995] Copeland, T., Koller, T., Murrin, J., Valuation, Measuring and managing the value of companies, second edition, McKinsey \& Company, Inc., John Wiley \& Sons, Inc., 1995.

[TCSEC, 1983], Department of Defense Computer Security Center, Trusted Computer Systems Evaluation, CSC-STD.011-83, DOD, Feb. 1983.

[TCSEC, 1985], Department of Defense Computer Security Center, Trusted Computer Systems Evaluation, DOD 5200.28-STD, NCSC, Dec. 1985.

[ESPD, 1992] Ericsson's Security Policy and Directives, Telefonaktiebolaget LM Ericsson, Corporate Security, Stockholm Sweden, July 1992.

[ITSEC, 1991], European Commission, Information Technology Security Evaluation Criteria, ITSEC, DG XIII/F, Luxembourg, 1991.

[Magnusson 1999], Magnusson, Christer: Hedging Shareholder Value in an IT dependent Business Society - the Framework BRITS, PhD dissertation, department of Computer and Systems Sciences, Stockholm University, report serie 99-015, Stockholm 1999

[Schoderbek et. al., 1985], Schoderbeck, Peter P., Schoderbek, Charles G., Kefalas, Asterios G., Management Systems: Conceptual Considerations, 3 ed., Business Publications, Inc., Texas, 1985.

[Yngström, 1996], Yngström, Louise, A Systemic-Holistic Approach to Academic

Programmes in IT Security, Ph.D.Thesis, Department of Computer and Systems Science, University of Stockholm and the Royal Institute of Technology, Stockholm, 1996. 